RESENHA

DOI: http://dx.doi.org/10.1590/So034-759020140611

\section{GESTÃO DE REDES ORGANIZACIONAIS DE ADVOGADOS DE IMIGRAÇÃO}

\author{
UNITING DIVERSE ORGANIZATIONS: MANAGING \\ GOAL-ORIENTED ADVOCACY NETWORKS \\ De Angel Saz-Carranza. New York: Routledge, 2012. 160 p. ISBN: 978-04-1589-902-4
}

O livro Uniting diverse organizations: managing goal-oriented advocacy networks examina os desafios conceituais da gestão de redes organizacionais. Combina pesquisa de campo qualitativa em quatro redes organizacionais de defesa envolvidas em debates sobre políticas de imigração nos Estados Unidos com uma leitura cuidadosa e aplicação da literatura sobre gestão e redes organizacionais. Saz-Carranza é professor do departamento de Estratégia e Administração Geral da Esade, onde também obteve seu doutorado em Gestão Pública. É diretor do ESADEgeo - Centro de Economia Global e Geopolítica e pesquisador do Instituto de Governança e Gestão Pública da mesma instituição catalã.

Em seu livro, o autor traz três contribuições importantes para o estudo de redes organizacionais: (a) aponta a unidade e a diversidade como preocupações centrais para os líderes de redes organizacionais e as dificuldades na gestão de redes; (b) apresenta um estudo emergente sobre o gerenciamento de rede "redes inteiras", uma maneira diferente de estudar a estrutura de rede (por exemplo, as conexões e as relações entre os membros da rede); e (c) discute os desafios de gerenciar as tensões entre unidade e diversidade nas literaturas sobre redes organizacionais e estudos clássicos organizacionais.

0 argumento central do livro é que qualquer rede de organizações deve promover a unidade entre os seus membros em relação aos objetivos da rede, à estratégia e à abordagem de implementação e, ao mesmo tempo, manter e explorar a diversidade entre os seus membros, a fim de gerar sinergia e recursos para apoiar o trabalho. A manutenção de um equilíbrio entre unidade e diversidade é crucial para “redes orientadas a objetivos", descritas no livro do Angel Saz-Carranza, porque são incorporações voluntárias de organizações independentes que se desenvolvem quando trabalham para o mesmo objetivo, explorando suas diferenças sem que se perca o seu sentido original. Assim como as organizações devem, simultaneamente, diferenciar e integrar os papéis pessoais (Lawrence \& Lorsch, Differentiation and integration in complex organizations: administrative science quarterly, 1967, 1-47), Saz-Carranza acredita que as redes precisam equilibrar a unidade e a diversidade entre os seus membros. Sem um senso de unidade, uma rede carece de propósito comum e estratégia; a falta de diversidade em sua composição, pelo contrário, pode limitar o seu conhecimento, acesso ao poder, legitimidade de representação e de recursos. 
Após a identificação dessas tensões na pesquisa de campo, o autor explora os desafios conceituais e práticos que os líderes de rede enfrentam na gestão das diferentes demandas que surgem a partir da necessidade de manter tanto a unidade quanto a diversidade.

As redes de advogados de imigração que Saz-Carranza pesquisou equilibram unidade e diversidade com uma combinação de diferentes atividades de liderança, muitas das quais são conhecidas na literatura de gerenciamento de redes. (a) Ativação: selecionar e atrair pessoas na organização para sustentar e garantir que os membros compartilhem objetivos, identidades comuns, e levem em conta uma composição diversificada nas diferenças de tamanho e complexidade, a seleção de ativação, as prioridades e os círculos eleitorais, as localizações geográficas, as estratégias políticas e as culturas nacionais. Um conjunto de conceitos e perspectivas teóricas sobre a forma como os indivíduos, grupos e sociedades se organizam, percebem e comunicam sua realidade ajuda os líderes a promover a unidade em torno da estrutura organizacional da rede, bem como as suas normas, regras e valores; (b) capacitação: uma nova atividade de liderança que Saz-Carranza identifica como a ajuda das redes nas transferências de conhecimentos e recursos. A capacitação ajuda as unidades da rede a aumentar seu ciclo de vida, a internalização de valores e significados, e interações construtivas e interdependência entre os membros, além de facilitar a comunicação e mediação.

O livro apresenta esse argumento de maneira concisa, em pouco mais de 150 páginas. Os capítulos 1 e 2 introduzem as bases conceituais e empíricas do estudo e descrevem as redes de advogados de imigração que forneceram os dados para a pesquisa. (No apêndice são apresentados detalhes sobre o projeto de pesquisa e procedimentos).
As partes mais importantes do livro são o capítulo 3, que apresenta o argumento teórico central e a elaboração da discussão teórica, e o capítulo 5 , sobre a tensão entre unidade e diversidade e a conclusão. Nesses capítulos, o autor brilhantemente situa a sua tese nas literaturas sobre redes e gestão organizacionais, tais como Agranoff e Mcguire (Collaborative public management. Georgetown University Press, 2003), Vangen e Huxham (The tangled web: unraveling the principle of common goals in collaborations. Journal of Public Administration Research and Theory, 22 (4), 731-760, 2012), além dos clássicos da teoria organizacional, como Simon, Thompson, e Lawrence e Lorsch. Com a sua visão geral das tensões entre unidade e diversidade, o capítulo 3 deveria ser leitura obrigatória em qualquer curso de redes organizacionais.

Esses capítulos sintetizam a essência do livro, diferenciando-o da maioria dos livros recentes sobre redes na Administração e gestão pública, entre os quais Agranoff (Managing within networks: adding value to public organizations. Georgetown University Press, 2007) e Goldsmith e Eggers (Governing by network: the new shape of the public sector. Brookings Institution Press, 2004). Rica em análises derivadas dos dados, a obra de Saz-Carranza deve inspirar os pesquisadores de rede no campo da Administração.

O capítulo 4 e, em menor medida, o capítulo 6 sofrem em comparação com o resto do livro, apesar de ambos os capítulos abordarem temas importantes, com informações úteis. 0 capítulo 4 examina como as redes desenvolvem recursos e poder para realizar seus objetivos, e o capítulo 6 descreve a facilitação dos processos de decisão compartilhada entre as organizações membros de cada rede. 0 tratamento do conceito sobre poder em ambos os capítulos é decepcionante por duas razões.

Em primeiro lugar, o livro não oferece análise dos conflitos de poder rela- cionados à raça e da política partidária, que estão no centro de muitos debates de imigração. Os leitores que desconhecem os conflitos em torno da política de imigração dos EUA podem terminar o livro pensando que o sucesso de redes de ação é simplesmente um produto do gerenciamento da rede interna, em vez de o cruzamento das atividades de todas as redes com os adversários políticos. No entanto, suspeito de que Saz-Carranza tenha uma riqueza de dados para desenvolver um artigo sobre o papel das redes de advogados na política de imigração dos EUA.

Em segundo lugar, o livro trata superficialmente dos desafios da gestão de redes que os desequilíbrios de poder e as diferenças entre fações criam. O capítulo 6 reconhece, em vários lugares, que os desequilíbrios de poder e fações exigem cuidado na facilitação das interações entre os membros da rede, especialmente em relação à ampla rede de tomada de decisões, mas não informa como as redes estudadas abordaram esse desafio. Embora a literatura de gerenciamento de rede trate da necessidade de administrar os desequilíbrios de poder, o capítulo fornece pouca elaboração conceitual de como se fazer isso. Em um livro cuja tese central é a importância de equilibrar a unidade e a diversidade entre os membros de uma rede, o assunto mereceria uma atenção mais detalhada.

Juntos, os pontos fortes e fracos deste livro destacam duas fronteiras no estudo da gestão de redes e liderança: as virtudes da infusão de análise empírica com uma rica base de conceitos teóricos e a necessidade de investigar as relações de poder e conflitos políticos dentro e entre redes organizacionais. Se os pesquisadores de redes organizacionais perseguirem qualquer uma dessas fronteiras com rigor e discernimento, o trabalho de Saz-Carranza já aponta um caminho. 